\title{
Sexual Fantasies Across Gender and Sexual Orientation in a Large Sample of Italian Young Adults: A Multiple Correspondence Analysis
}

MATTIA NESE ( $\nabla$ m.nese@milano-sfu.it)

Sigmund Freud PrivatUniversitat - Milan https://orcid.org/0000-0003-1422-8199

Greta Riboli

Sigmund Freud PrivatUniversitat - Milan

Gianni Brighetti

Sigmund Freud PrivatUniversitat - Milan

Raffaele Visciano

Sigmund Freud PrivatUniversitat - Milan

Daniel Giunti

Centro integrato di sessuologia clinica "Il Ponte", Florence

Rosita Borlimi

Sigmund Freud PrivatUniversitat - Milan

\section{Research Article}

Keywords: Sexual fantasy, Gender, Sexual orientation, Young adults, Multiple correspondence analysis

Posted Date: February 6th, 2021

DOI: https://doi.org/10.21203/rs.3.rs-168907/v1

License: (c) (i) This work is licensed under a Creative Commons Attribution 4.0 International License. Read Full License 


\section{Abstract}

Differences in the content of sexual fantasies across gender have been widely documented, while less attention was given to the role of sexual orientation. Furthermore, previous studies focused on statistical differences in the prevalence of broad themes, neglecting the role of single fantasies. The current study aimed to increase the knowledge about sexual fantasies in heterosexual, homosexual, and bisexual men and women. A descriptive approach that allows representing the patterns of fantasies reported by different groups using Multiple Correspondence Analysis (MCA) is presented. A sample of 3,136 of young adults, 1,754 women (Mage $=22.50, S D=1.72$, range 18-25) and 1,382 men (Mage $=22.50, S D=1.70$, range 18-25), completed an online questionnaire assessing the presence of 29 different sexual fantasies. The prevalence of each fantasy among each group is shown. Also, relationships between fantasies and the distribution of groups along the two principal dimensions highlighted by MCA are represented. Heterosexuals women reported fewer fantasies and showed opposite patterns of response compared to heterosexual men. There was a substantial overlapping in the fantasies reported by gay and bisexual men, while responses of lesbian and bisexual women were relatively more differentiated. These results indicate that sexual orientation has a different impact on the sexual fantasies of men and women.

\section{Introduction}

Sexual fantasies have been generally defined as sexually arousing mental images that can emerge spontaneously (i.e., sexual daydreaming) or be evoked intentionally and consciously manipulated (Leitenberg \& Henning, 1995; Purifoy et al., 1992). The central role of sexual fantasies in sexual life has been well-established, as they may reflect past experiences and influence future sexual behaviors (Fontanesi \& Renaud, 2014).

It is worth noting that sexual fantasies do not always mirror real sexual desires. For example, although women frequently fantasize about being raped, it does not mean they actually wish to be raped (Bivona et al., 2012; Joyal et al., 2015). Thus, fantasies remain part of a fictional world governed by the protagonist, who can use them to escape from social and moral constraints (Ellis \& Symons, 1990).

Sexual fantasy is important for sexual well-being and has benefits for both single individuals and partners. For example, dyadic fantasizing is associated with heightened desire and increases engagement in relationship-promoting behaviors (Birnbaum et al., 2019). A recent paper exploring the impact of the COVID-19 pandemic on sexuality (Lopes et al., 2020) underlined the role of fantasies to overcome periods of forced separation from steady partners and fulfill sexual pleasure during social isolation. Furthermore, sexual fantasies emerged as a strategy to cope with changes in sexual functioning by older adults (Ayalon et al., 2019).

Several tools were created to assess the prevalence, frequency, and content of sexual fantasies. For example, the Sex Fantasy Questionnaire (Wilson, 1988) includes 40 items that were grouped into four main themes: Exploratory, Intimate, Impersonal, Sadomasochistic. Anzani and Prunas (2020) performed 
a factor analysis of the Sexual Fantasy Questionnaire (Bogaert et al., 2015), highlighting nine factors from a list of 62 items. The Erotic Imagery Questionnaire (EIQ) (Panzeri et al., 2015) is an Italian questionnaire that assesses sexual fantasies based on five major factors: transgressive theme, emotional-romantic theme, dominance/submission theme, variety of partners, and sexually explicit images. While being useful to describe groups according to broad features, the labels assigned to themes are only partially accurate in describing the content of fantasies. Moreover, when measuring sexual fantasies, it is important to distinguish between the frequency of occurrence (Wilson, 1988) from the arousing potential (Anzani \& Prunas, 2020; Bogaert et al., 2015) and how typical the contents are (Tortora et al., 2020). Studies employing questionnaires that differ in their questioning approach (despite all declaring to measure sexual fantasies) are be easily comparable. This picture is even more complicated by the presence of unconventional fantasies, sometimes labeled as "paraphilias" (e.g., voyeurism, frotteurism, fetishism), and considered deviant from the norm, although recent studies showed they are quite common (Bártová et al., 2021; Joyal, 2015; Joyal et al., 2015; Tripodi et al., 2015). Furthermore, the peculiar characteristics of sexual and gender minorities (e.g., nonbinary, asexual) and the influence of sociocultural factors challenge the use of rigid standardized psychometric tools.

\section{Gender differences in sexual fantasies}

Several gender differences in the prevalence and content of sexual fantasies have been reported in the literature. Men seem to have more fantasies than women (Ellis \& Symons, 1990; Leitenberg \& Henning, 1995; Wilson \& Lang, 1981), at least during masturbation, while the difference disappears during intercourse and sexual daydreaming (Baumeister et al., 2001; Leitenberg \& Henning, 1995). Men are more likely to fantasize about explicit images and impersonal relationships (Ellis \& Symons, 1990; Leitenberg \& Henning, 1995; Zurbriggen \& Yost, 2004), while women tend to focus on emotional, romantic contents (Bogaert et al., 2015; Carpenter et al., 2008; Leitenberg \& Henning, 1995; Lindley et al., 2020; Yost \& Zurbriggen, 2006). Another widely reported difference concerns the role of the protagonist: men fantasize about having dominant and active roles while women imagine themselves as submissive and passive in a scenario in which they play the role of their partner's object of desire (Leitenberg \& Henning, 1995; Wilson \& Lang, 1981; Zurbriggen \& Yost, 2004). However, these results have not always been replicated or showed substantial within-group differences (Allen, 2003; Anzani \& Prunas, 2020), indicating that even consolidated sexual scripts are not always reflected by fantasies and could be susceptible to changes.

Men are more likely to fantasize about having sex with more than one sexual partner, participating in an orgy, or having group sex (Anzani \& Prunas, 2020; Ellis \& Symons, 1990; Joyal et al., 2015; Wilson \& Lang, 1981), but also several fantasies about consensual nonmonogamy (Lehmiller, 2020). It is also more likely for men to fantasize about their partners being extremely beautiful and attractive (Anzani \& Prunas, 2020; Bogaert et al., 2015), while women tend to have more sexual fantasies in which they render their bodies attractive to their sexual partners, through clothing or gestures (Bogaert et al., 2015). 


\section{Sexual orientation differences}

A relatively small amount of studies investigated sexual fantasies across sexual orientation. The most commonly reported fantasies by gay men include images of sexual anatomy, forced sexual intercourses with men and women (forcing or being forced or both), sexual intercourses with a woman, idyllic sexual intercourses with unknown men, group sex, performing and receiving oral sex, anal sex, erotic films, masturbating another man (Cacioppo et al., 2009; Masters et al., 1982; Price et al., 1985). These studies give us general information about the sexual fantasies of gay men, but they did not investigate any direct comparison with heterosexual men. In early contributions regarding differences between heterosexual and gay men, the idea that males share the same pattern of preferences regardless of their sexual orientation and cultural differences was prevalent (Masters et al., 1982; Price et al., 1985). However, more recent contributions showed that sexual orientation could influence the content of sexual fantasies (for a recent review, see Nimbi et al., 2020).

Gay men reported exploratory (e.g., "Participating in an orgy"), intimate (e.g., "Having intercourse with a loved partner"), and impersonal (e.g., "Using objects for stimulation") sexual fantasies more frequently than heterosexual men while there is no difference in the sadomasochistic category (Bhugra et al., 2006).

A recent Italian study (Tortora et al., 2020) reported that lesbian women have slightly higher rates of transgressive sexual fantasies and lower rates of emotional-romantic ones than heterosexual women; also, gay men fantasized more about the variety of partners, dominance/submission, explicit sexuality themes, and less about transgressive and emotional/romantic themes than heterosexual men (Tortora et al., 2020).

Very few studies included bisexual individuals in their samples. Robinson and Parks (2004) did not find significant differences in the sexual fantasies between heterosexual and bisexual women. Gay men fantasize about having more than one sexual partner more often than heterosexual men but less than bisexual men (Schmitt et al., 2003).

Both gay and heterosexual men shared cuckolding fantasies (obtaining sexual arousal from the experience of a romantic partner engaging in sexual activity with someone else), even though the former reported fewer interracial and BDSM themes than the latter (Lehmiller et al., 2018).

In general, the studies mentioned above hint at the different roles of gender and sexual orientation in determining the sexual fantasy's contents. Thus, these factors should not be taken as single determinants of sexual fantasies as their interaction may highlight different patterns of contents.

\section{The present study}


The present study aims to integrate previous results, focusing on the influence of both gender and sexual orientation on the content of arousing sexual fantasies. In particular, the inclusion of bisexual men and women fills the gap in the scientific literature.

Moreover, the choice of assessment tools and statistical analysis has several implications that need to be acknowledged. First, fantasies change over time individually and collectively (Bianchi, 2017; Harvey \& Jeglic, 2020). Thus, as qualitative research highlights new themes and tendencies, psychometric tools should be adapted according to the object of interest. While the use of standardized questionnaires based on broad themes ensures cross-study comparisons, it may not be appropriate to highlight novel tendencies.

Second, we may want to assess fantasies that are not included in standardized questionnaires; for example, if we want to study relatively less conventional fantasies (e.g., paraphilic) or if we observe groups and communities that present particular aspects compared to the general population (Antonsen et al., 2020; Yule et al., 2017).

In this context, the use of flexible tools and an explorative approach supported by qualitative research (Lindley et al., 2020) could be more suitable.

Another methodological remark concerns the questioning approach used in the present study. Some questionnaires ask to rate the frequency (Wilson, 1988) or the intensity (Joyal, 2015) of sexual fantasies. These methods rely upon excellent abilities of thought monitoring and memory. However, people may find it difficult to assign numbers/labels (for example, on a Likert scale) to their experience, especially if fantasies occupy a small amount of their time. Instead, it may be easier for people to decide if a certain fantasy belongs to their imagery repertoire or not. For this reason, the questions employed here required to respond 'Yes' or 'No' whether each fantasy was present or not. Of course, this choice also has implications for statistical tests to be used to analyze results.

For all these reasons, in the present paper, we propose a flexible method to explore patterns of sexual fantasies reported among six different groups given by the combination of gender (men and women) and sexual orientation (heterosexual, homosexual, and bisexual), namely using an ad hoc questionnaire and Multiple Correspondence Analysis (MCA) to analyze dichotomic responses. To our knowledge, only one study employed MCA to explore sexual fantasies (Joyal, 2015). This method allows visualizing each fantasy's contribution, highlighting relationships between single fantasies that may not emerge when broad themes are assumed a priori.

\section{Method}

\section{Participants}

Data were collected using "Google Forms" through an online questionnaire available from May 2019 to December 2019. Participants were randomly recruited through advertising on various websites and social 
networks (e.g., Facebook) and participated in the research on a voluntary basis. Inclusion criteria were being at least 18 years old, understanding the Italian language, and having a sexual orientation that was either heterosexual, homosexual, or bisexual; an exclusion criterion for the present study was reporting non-binary gender identity. The questionnaire took about 10 minutes to complete. Informed consent was obtained from each participant at the beginning of the survey. Ethics approval was obtained by the Ethics Committee of Sigmund Freud University in accordance with the ethical standards of the Declaration of Helsinki (2013).

\section{Measures}

An ad hoc online survey was developed to investigate sexual fantasies. It included socio-demographic questions about sex assigned at birth, self-perceived gender, age, sexual orientation, nationality, age, educational level, and employment situation.

\section{Heterosexual-Homosexual Rating Scale}

The sexual orientation of each participant was assessed on a continuum that ranged from 0 ("Exclusively heterosexual") to 6 ("Exclusively homosexual") using the Heterosexual-Homosexual Rating Scale (Kinsey et al., 1948). Specifically, values from 0 to 2 were considered indicators of heterosexuality; values from 4 to 6 were assigned to homosexuality; the value 3 corresponded to bisexuality.

\section{Sexual fantasies}

Twenty-nine statements were included in the survey to investigate sexual fantasies. All the statements were introduced by the sentence "I am sexually aroused when I fantasize about...", then, each fantasy was presented. For example, "I am sexually aroused when I fantasize about being strangled by the partner while having sex". Participants were instructed to answer 'Yes' or 'No'.

Sexual fantasies included in the questionnaire were selected from previously used questionnaires and integrated with ad hoc questions. In choosing the questions, we decided to focus more on the object of the fantasy (i.e., activities) rather than on the role of the person fantasizing (e.g., active/passive). For some fantasies, participants could imagine having different roles while keeping the object of the fantasy constant.

The contents of fantasies included in the questionnaire and translated from the original Italian version are listed in Table 1 with the name assigned to correspondent variables. From now on, variable names listed in Table 1 will be used when referring to sexual fantasies.

\section{STATISTICAL ANALYSIS}


We employed an explorative approach to see how gender and sexual orientation influence the prevalence of sexual fantasies. To characterize different groups, not only the presence of specific fantasies was taken into account but also their absence (i.e., whether participants responded 'Yes' or 'No). MCA is generally used to analyze data sets from surveys. The goal of MCA here is to: (i) identify the associations between different fantasies and highlight the main dimensions given by associated fantasies; (ii) represent groups of individuals according to the pattern of responses (i.e., types of fantasies). The $\mathrm{R}$ packages FactoMineR (for the MCA analysis) and factoextra (for data visualization) were used (Lê et al., 2008).

\section{Results}

A total of 3,173 people completed the online survey. Of these, 37 participants were excluded because they reported a non-binary gender $(n=6)$ and/or a sexual orientation that was neither heterosexual, homosexual, or bisexual $(n=36)$. Therefore, the final sample was composed of 3,136 participants, 1754 women $\left(55.9 \%, M_{\text {age }}=22.50, S D=1.72\right.$, range $18-25$ years old $)$ and 1,382 men $\left(44.1 \%, M_{\text {age }}=22.50, S D=\right.$ 1.70, range 18-25 years old). According to Kinsey's scale (Kinsey et al., 1948), 92.07\% of the women and $92.04 \%$ of the men were heterosexual; $2.34 \%$ of the women and $5.72 \%$ of the men were homosexual; $5.59 \%$ of the women and $2.24 \%$ of the men were bisexual.

The prevalence of fantasies among the overall sample and subgroups is reported in Figure 1. Hetero (77.59\%), OralSex (76.62\%), and RomanticSex (75.35\%) were the most common fantasies, while TransMe (1.00\%), Prostitute (1.48\%), and Elderly (1.61\%) were the less common ones.

The MCA highlighted the presence of several dimensions given the association of particular fantasies. The first dimension (Dim1) accounted for $13.07 \%$ of the total explained variance and was mainly given by the contribution of the following fantasies: EjaculateOnFace, EjaculateOnBody, AnalGiver, Voyeur, StrangleOther. The second dimension (Dim2) accounted for $7.40 \%$ of the total explained variance and was mainly given by the contribution of the following fantasies: ToysMasturb, Homo, AnalReceiver, StrangleMe, ToysSex. Taken together, the first and the second dimension explained $20.46 \%$ of the total variance. From the third dimension onward, the proportion of explained variation reached a plateau, and dimensions were formed by very infrequent fantasies (i.e., Dim3: Elderly, Overweight; Dim4: TransMe, TransOther) with high specificity. For these reasons, the subsequent analyses and graphical representations focused on the combination of the first two dimensions only. Figure 2 shows the combined correlation of each fantasy with the two main dimensions Dim1 and Dim2. Figure 3 shows a geometrical representation of responses where spatially closer responses are more strongly associated with individual patterns of responses. Here, positive (variables ending with "_y") and negative (variables ending with "_n”) responses a plotted in opposite quadrants, to the right and the left of the plot origin, respectively. The color of each fantasy indicates its percentage contribution to the two dimensions.

Figure 4 shows a geometrical representation of individuals and groups based on gender and sexual orientation along the two main dimensions Dim1 and Dim2. 
By looking at both Figures 2 and 3 , it is possible to describe groups according to their patterns of responses.

Heterosexual men and women being in opposite quadrants reflect opposite tendencies in their sexual fantasies: men were more likely represented by Dim1 (e.g., fantasizing more about giving anal sex, ejaculate on partner's body and face, strangle the partner and voyeurism) while less by Dim2 (e.g., having sex and masturbating using sex toys, having sex with someone of the same sex, receiving anal sex, being strangled by the partner); women were more likely represented by Dim2 than Dim1.

The distribution of homosexual and bisexual men shows that they share a very similar fantasy pattern, although, given the relatively lower numerosity of these two groups (particularly for bisexual men), their representation is less robust. Interestingly, we do not observe the same overlapping for lesbian and bisexual women, with bisexual women being the most represented group by Dim2 while lesbian women share similarities with both bisexual and heterosexual women. In general, heterosexual men appear to be relatively isolated from the other groups, being the only group negatively represented along with Dim 2, while heterosexual women reported higher rates of negative responses for the emerged fantasies.

\section{Discussion}

The present paper aimed to explore arousing sexual fantasies among men and women according to their sexual orientation. MCA allowed to observe what fantasies were more strongly associated with each other and highlighted two principal dimensions subsequently used to characterize groups.

Some of these associations show commonalities with previously observed themes, while other relationships were less predictable. At a first look, Dim1 and Dim2 may resemble themes and roles conceptualized by previous studies (Wilson \& Lang, 1981; Zurbriggen \& Yost, 2004). In particular, fantasies of dominance/activeness (represented by Dim1) have been mainly reported by heterosexual men, while fantasies of submission/passiveness (represented by Dim2) characterize women (Leitenberg \& Henning, 1995; Wilson \& Lang, 1981; Zurbriggen \& Yost, 2004).

However, some fantasies positively contributing to Dim1 and Dim2 elude this simple categorization. For example, fantasizing about masturbation with sex toys (ToysMasturb) has not been typically associated with submission/passiveness themes and has been rarely investigated. Lehmiller (2019) included fantasies about sex toys among the most frequently reported fantasies by non-binary people, along with scenes of kink sex, anal sex, polyamory, and forced sex. This result demonstrates the advantages of using an exploratory approach without a priori categories as we can also observe associations between fantasies that typically belong to different themes/categories.

Regarding heterosexual women, it is possible to note that they reported less arousing contents than any other group, as previous studies observed (Ellis \& Symons, 1990; Leitenberg \& Henning, 1995; Wilson \& Lang, 1981). This result may indicate that the content of their fantasies varies less than other groups or that they were poorly described by the fantasies considered in this study. 
Interestingly, in the present study, all groups reported similar rates of fantasies with romantic contents, in contrast with previous studies reporting higher rates of emotional-romantic contents among heterosexual women than heterosexual men (Bogaert et al., 2015; Carpenter et al., 2008; Leitenberg \& Henning, 1995; Lindley et al., 2020; Yost \& Zurbriggen, 2006) and lesbian women (Tortora et al., 2020).

The origin of gender differences seems to rely on evolutionary and sociocultural factors (Fontanesi \& Renaud, 2014). For example, a higher rate of sex guilt and religiosity in women could affect both the variety and the willingness to report sexual fantasies (Ahrold et al., 2011; Fontanesi \& Renaud, 2014; Goldey et al., 2014). Instead, differences linked to sexual orientation are less clearly interpretable and seem to vary more across studies. The initial idea of men sharing the same fantasies regardless of their sexual orientation (Masters et al., 1982) seems to be disconfirmed by these results and other recent studies (Nimbi et al., 2020; Tortora et al., 2020), possibly indicating an easing of social pressure that drives gay and bisexual men towards traditional masculine sexual stereotypes.

Given the high numerosity of our sample, the analyses highlighted the prevalence of mainstream fantasies. Different results may emerge when focusing on minorities with peculiar sexual behaviors (Nordling et al., 2014).

Some limitations can be acknowledged in the present study. Firstly, using random online recruitment of participants resulted in considerably different numerosity of subgroups within the sample. In particular, homosexuals and bisexuals were less represented than heterosexuals, making the assumptions about their results less robust. Secondly, the choice of the fantasies included in the survey, although based on previous research, was arbitrary; other authors could choose to include different fantasies in their study. While constituting a potential problem for cross-study comparisons, the method employed here showed that this could also be seen as an opportunity to build a flexible assessment tool.

\section{Conclusions}

Research about the influence of both gender and sexual orientation is limited, outdated, or employed relatively small samples. Furthermore, past studies tended to compare groups according to the prevalence of broad categories of fantasies (i.e., themes), assuming that each fantasy belongs exclusively to a theme. The risk of using a priori categories is to mask the association between single fantasies belonging to different categories. The current paper showed that it is possible to characterize groups in terms of fantasies patterns while preserving the value of single fantasies. Besides, graphical representations derived by MCA can be useful to observe relationships between different fantasies and intragroup variability.

Some results were coherent with previous studies while others were not, thus, underlining the importance of conducting systematic research to capture potential changes over time linked to sociocultural factors. Future studies should also focus on sexual and gender minorities as they may present significant differences compared to the rest of the population (Antonsen et al., 2020; Anzani \& Prunas, 2020; Lindley 
et al., 2020). Besides, while the present study focused on two principal dimensions, more than two dimensions could be taken into account to represent a higher amount of variability within the sample.

In conclusion, the study of sexual fantasies is relevant for multiple reasons linked to sexual well-being. For example, imagery-based techniques are widely used in sex therapy to enhance sexuality and overcome sexual difficulties and dysfunctions. Thus, the contribution of psychological research to the knowledge on this topic is crucial for promoting sexual health.

\section{Declarations}

\section{Funding}

The authors received no funding for the present research.

\section{Availability of data and material (data transparency)}

Data are available upon reasonable request to the corresponding author.

\section{Code availability}

The R packages used for this research are freely available on the CRAN repository website: https://cran.rproject.org/ .

\section{Compliance with ethical standards}

\section{Conflicts of interest/Competing interests}

None.

\section{Ethical Approval}

All procedures performed in studies involving human participants were in accordance with the ethical standards of the Institutional and/or National Research Committee and with the 1964 Helsinki declaration and its later amendments or comparable ethical standards.

Ethics approval was obtained by the Ethics Committee of Sigmund Freud University.

\section{Consent to participate}

Informed consent was obtained from all individual participants included in the study.

\section{References}

Ahrold, T. K., Farmer, M., Trapnell, P. D., \& Meston, C. M. (2011). The relationship among sexual attitudes, sexual fantasy, and religiosity. Archives of Sexual Behavior, 40(3), 619-630. 
https://doi.org/10.1007/s10508-010-9621-4

Allen, L. (2003). Girls Want Sex, Boys Want Love: Resisting Dominant Discourses of (Hetero) Sexuality. Sexualities, 6(2), 215-236. https://doi.org/10.1177/1363460703006002004

Antonsen, A. N., Zdaniuk, B., Yule, M., \& Brotto, L. A. (2020). Ace and Aro: Understanding Differences in Romantic Attractions Among Persons Identifying as Asexual. Archives of Sexual Behavior, 49(5), 16151630. https://doi.org/10.1007/s10508-019-01600-1

Anzani, A., \& Prunas, A. (2020). Sexual Fantasy of Cisgender and Nonbinary Individuals: A Quantitative Study. Journal of Sex \& Marital Therapy, 46(8), 763-772.

https://doi.org/10.1080/0092623X.2020.1814917

Ayalon, L., Gewirtz-Meydan, A., \& Levkovich, I. (2019). Older Adults' Coping Strategies With Changes in Sexual Functioning: Results From Qualitative Research. Journal of Sexual Medicine, 16(1), 52-60. https://doi.org/10.1016/j.jsxm.2018.11.011

Bártová, K., Androvičová, R., Krejčová, L., Weiss, P., \& Klapilová, K. (2021). The Prevalence of Paraphilic Interests in the Czech Population: Preference, Arousal, the Use of Pornography, Fantasy, and Behavior. The Journal of Sex Research, 58(1), 86-96. https://doi.org/10.1080/00224499.2019.1707468

Baumeister, R. F., Catanese, K. R., \& Vohs, K. D. (2001). Is There a Gender Difference in Strength of Sex Drive? Theoretical Views, Conceptual Distinctions, and a Review of Relevant Evidence. Personality and Social Psychology Review, 5(3), 242-273. https://doi.org/10.1207/S15327957PSPR0503_5

Bhugra, D., Rahman, Q., \& Bhintade, R. (2006). Sexual fantasy in gay men in India: A comparison with heterosexual men. Sexual and Relationship Therapy, 21(2), 197-207.

https://doi.org/10.1080/14681990600554207

Bianchi, T. (2017). Italian Female Sexual Fantasies: Do They Really Differ From Men's and Have They Changed in Time? The Journal of Sexual Medicine, 14(5), e318.

https://doi.org/10.1016/j.jsxm.2017.04.521

Birnbaum, G. E., Kanat-Maymon, Y., Mizrahi, M., Recanati, M., \& Orr, R. (2019). What Fantasies Can Do to Your Relationship: The Effects of Sexual Fantasies on Couple Interactions. Personality and Social Psychology Bulletin, 45(3), 461-476. https://doi.org/10.1177/0146167218789611

Bivona, J. M., Critelli, J. W., \& Clark, M. J. (2012). Women's Rape Fantasies: An Empirical Evaluation of the Major Explanations. Archives of Sexual Behavior, 41(5), 1107-1119. https://doi.org/10.1007/s10508012-9934-6

Bogaert, A. F., Visser, B. A., \& Pozzebon, J. A. (2015). Gender Differences in Object of Desire SelfConsciousness Sexual Fantasies. Archives of Sexual Behavior, 44(8), 2299-2310.

https://doi.org/10.1007/s10508-014-0456-2

Page $11 / 19$ 
Cacioppo, M., Vizzari, V., Corica, F., Maestri, V., \& Simonelli, C. (2009). An exploratory study on male homosexual erotic imagery. Sexologies, 18(1), 44-50. https://doi.org/10.1016/j.sexol.2007.12.007

Carpenter, D., Janssen, E., Graham, C., Vorst, H., \& Wicherts, J. (2008). Women's Scores on the Sexual Inhibition/Sexual Excitation Scales (SIS/SES): Gender Similarities and Differences. Journal of Sex Research, 45(1), 36-48. https://doi.org/10.1080/00224490701808076

Ellis, B. J., \& Symons, D. (1990). Sex Differences in Sexual Fantasy: An Evolutionary Psychological Approach. The Journal of Sex Research, 27(4), 527-555. https://doi.org/10.1080/00224499009551579

Fontanesi, L., \& Renaud, P. (2014). Sexual presence: Toward a model inspired by evolutionary psychology. New Ideas in Psychology, 33(1), 1-7. https://doi.org/10.1016/j.newideapsych.2013.10.001

Goldey, K. L., Avery, L. R., \& Van Anders, S. M. (2014). Sexual fantasies and gender/sex: A multimethod approach with quantitative content analysis and hormonal responses. Journal of Sex Research, 51(8), 917-931. https://doi.org/10.1080/00224499.2013.798611

Harvey, T. A., \& Jeglic, E. L. (2020). Attenuation of Deviant Sexual Fantasy across the Lifespan in United States Adult Males. Psychiatry, Psychology and Law, 27(2), 246-264.

https://doi.org/10.1080/13218719.2020.1719376

Joyal, C. C. (2015). Defining "Normophilic" and "Paraphilic" Sexual Fantasies in a Population-Based Sample: On the Importance of Considering Subgroups. Sexual Medicine, 3(4), 321-330. https://doi.org/10.1002/sm2.96

Joyal, C. C., Cossette, A., \& Lapierre, V. (2015). What Exactly Is an Unusual Sexual Fantasy? The Journal of Sexual Medicine, 12(2), 328-340. https://doi.org/10.1111/jsm.12734

Kinsey, A. C., Pomeroy, W. B., \& Martin, C. E. (1948). Sexual behavior in the human male. Philadelphia: Saunders.

Lê, S., Josse, J., \& Husson, F. (2008). FactoMineR: An R Package for Multivariate Analysis. Journal of Statistical Software, 25(1). https://doi.org/10.18637/jss.v025.i01

Lehmiller, J. J. (2019, April 8). The sexual fantasies of people with non-binary gender identities. Sex \& psychology. https://www.lehmiller.com/blog/2019/4/8/what-do-gender-non-binarypeople-fantasizeabout

Lehmiller, J. J. (2020). Fantasies About Consensual Nonmonogamy Among Persons in Monogamous Romantic Relationships. Archives of Sexual Behavior, 49(8), 2799-2812. https://doi.org/10.1007/s10508-020-01788-7

Lehmiller, J. J., Ley, D., \& Savage, D. (2018). The Psychology of Gay Men's Cuckolding Fantasies. Archives of Sexual Behavior, 47(4), 999-1013. https://doi.org/10.1007/s10508-017-1096-0 
Leitenberg, H., \& Henning, K. (1995). Sexual fantasy. Psychological Bulletin, 117(3), 469-496. https://doi.org/10.1037/0033-2909.117.3.469

Lindley, L. M., Anzani, A., Prunas, A., \& Galupo, M. P. (2020). Sexual fantasy across gender identity: a qualitative investigation of differences between cisgender and non-binary people's imagery. Sexual and Relationship Therapy, 1-22. https://doi.org/10.1080/14681994.2020.1716966

Lopes, G. P., Vale, F. B. C., Vieira, I., da Silva Filho, A. L., Abuhid, C., \& Geber, S. (2020). COVID-19 and Sexuality: Reinventing Intimacy. Archives of Sexual Behavior, 49(8), 2735-2738. https://doi.org/10.1007/s10508-020-01796-7

Masters, W. H., Johnson, V. E., Översättning, S., \& Lisper, H.-O. (1982). Homosexuality in perspective. Scandinavian Journal of Behaviour Therapy, 11(1), 54-56.

https://doi.org/10.1080/16506078209456227

Nimbi, F. M., Ciocca, G., Limoncin, E., Fontanesi, L., Uysal, Ü. B., Flinchum, M., Tambelli, R., Jannini, E. A., \& Simonelli, C. (2020). Sexual Desire and Fantasies in the LGBT+ Community: Focus on Lesbian Women and Gay Men. Current Sexual Health Reports, 12(3), 153-161. https://doi.org/10.1007/s11930-02000263-7

Nordling, N., Sandnabba, N. K., Santtila, P., \& Alison, L. (2014). Differences and similarities between gay and straight individuals involved in the sadomasochistic subculture. Sadomasochism: Powerful Pleasures, November 2014, 41-57. https://doi.org/10.4324/9781315801582

Panzeri, M., Fontanesi, L., and Gardin, E. (2015). L'Erotic Imagery Questionnaire (EIQ). Una prima valutazione psicometrica. Riv. Di Sessuologia Clin. 39, 112- 127.

Price, J. H., Allensworth, D. D., \& Hillman, K. S. (1985). Comparison of sexual fantasies of homosexuals and of heterosexuals. Psychological Reports, 57(3 I), 871-877.

https://doi.org/10.2466/pr0.1985.57.3.871

Purifoy, F. E., Grodsky, A., \& Giambra, L. M. (1992). The relationship of sexual daydreaming to sexual activity, sexual drive, and sexual attitudes for women across the life-span. Archives of Sexual Behavior, 21(4), 369-385. https://doi.org/10.1007/BF01542026

Robinson, J. D., \& Parks, C. W. (2004). Lesbian and bisexual women's sexual fantasies, psychological adjustment, and close relationship functioning. Journal of Psychology and Human Sexuality, 15(4), 185203. https://doi.org/10.1300/J056v15n04_03

Schmitt, D. P., Alcalay, L., Allik, J., Ault, L., Austers, I., Bennett, K. L., Bianchi, G., Boholst, F., Borg Cunen, M. A., Braeckman, J., Brainerd, E. G., Caral, L. G. A., Caron, G., Martina Casullo, M., Cunningham, M., Daibo, I., De Backer, C., De Souza, E., Diaz-Loving, R., ... Zupanèiè, A. (2003). Universal Sex Differences in the Desire 
for Sexual Variety: Tests from 52 Nations, 6 Continents, and 13 Islands. Journal of Personality and Social Psychology, 85(1), 85-104. https://doi.org/10.1037/0022-3514.85.1.85

Tortora, C., D'Urso, G., Nimbi, F. M., Pace, U., Marchetti, D., \& Fontanesi, L. (2020). Sexual Fantasies and Stereotypical Gender Roles: The Influence of Sexual Orientation, Gender and Social Pressure in a Sample of Italian Young-Adults. Frontiers in Psychology, 10(January), 1-10.

https://doi.org/10.3389/fpsyg.2019.02864

Tripodi, F., Eleuteri, S., Giuliani, M., Rossi, R., Livi, S., Petruccelli, I., Petruccelli, F., Daneback, K., \& Simonelli, C. (2015). Unusual online sexual interests in heterosexual Swedish and Italian university students. Sexologies, 24(4), e84-e93. https://doi.org/10.1016/j.sexol.2015.03.003

Wilson, G. D. (1988). Measurement of sex fantasy. Sexual and Marital Therapy, 3(1), 45-55. https://doi.org/10.1080/02674658808407692

Wilson, G. D., \& Lang, R. J. (1981). Sex differences in sexual fantasy patterns. Personality and Individual Differences, 2(4), 343-346. https://doi.org/10.1016/0191-8869(81)90093-3

Yost, M. R., \& Zurbriggen, E. L. (2006). Gender differences in the enactment of sociosexuality: An examination of implicit social motives, sexual fantasies, coercive sexual attitudes, and aggressive sexual behavior. Journal of Sex Research, 43(2), 163-173. https://doi.org/10.1080/00224490609552311

Yule, M. A., Brotto, L. A., \& Gorzalka, B. B. (2017). Sexual Fantasy and Masturbation Among Asexual Individuals: An In-Depth Exploration. Archives of Sexual Behavior, 46(1), 311-328.

https://doi.org/10.1007/s10508-016-0870-8

Zurbriggen, E. L., \& Yost, M. R. (2004). Power, desire, and pleasure in sexual fantasies. The Journal of Sex Research, 41(3), 288-300. https://doi.org/10.1080/00224490409552236

\section{Tables}

\section{Table 1}

Contents of assessed arousing sexual fantasies and assigned variables names. 


\begin{tabular}{lll}
\hline$\#$ & Variable name & Content of fantasy \\
\hline 1 & AnalGiver & Anal sex as giver (included with strap-on) \\
2 & AnalReceiver & Anal sex as receiver \\
3 & Clergy & Clergymen/women (e.g., priests, nuns etc.) \\
4 & EjaculateOnBody & Ejaculating on my partner's body or vice versa \\
5 & EjaculateOnFace & Ejaculating on my partner's face or vice versa \\
6 & Elderly & Having sex with elderly people \\
7 & Frotteur & Rubbing myself against a non-consenting person \\
8 & Hentai & Cartoons with sexual contents (for example, hentai) \\
9 & Hetero & Having sex with a person of a different sex \\
10 & Homo & Having sex with a person of the same sex as myself \\
11 & OralSex & Oral sex (fellatio, cunnilingus) \\
12 & Overweight & Having sex with overweight/obese people \\
13 & Prostitute & Paying a prostitute for sex \\
14 & PublicSex & Having sex in public places (for example parks, toilets, etc.) \\
15 & RomanticSex & Having romantic and intimate sex \\
16 & StrangleMe & Being strangled by the partner while having sex \\
17 & StrangleOther & Strangling the partner while having sex \\
18 & Tattoos & Having sex with someone who has tattoos \\
19 & ToysMasturb & Using sex toys during masturbation \\
20 & ToysSex & Using sex toys during sex \\
21 & TransMe & Having sex while dressed as someone of the opposite sex \\
22 & TransOther & Having sex with someone dressed as someone of the opposite sex \\
23 & TwentyYearsOlder & Having sex with someone at least twenty years older than me \\
24 & TwoOrMore & Having sex with other two or more people at the same time \\
25 & Underweight & Having sex with underweight people \\
26 & Voyeur & Watching someone naked/having sex without them knowing \\
27 & WatchMasturb & Watching someone masturbating \\
28 & WatchWithConsent & Watching someone naked/having sex with their consent \\
29 & WetClothes & Watching someone wearing wet clothes \\
\hline & &
\end{tabular}

\section{Figures}



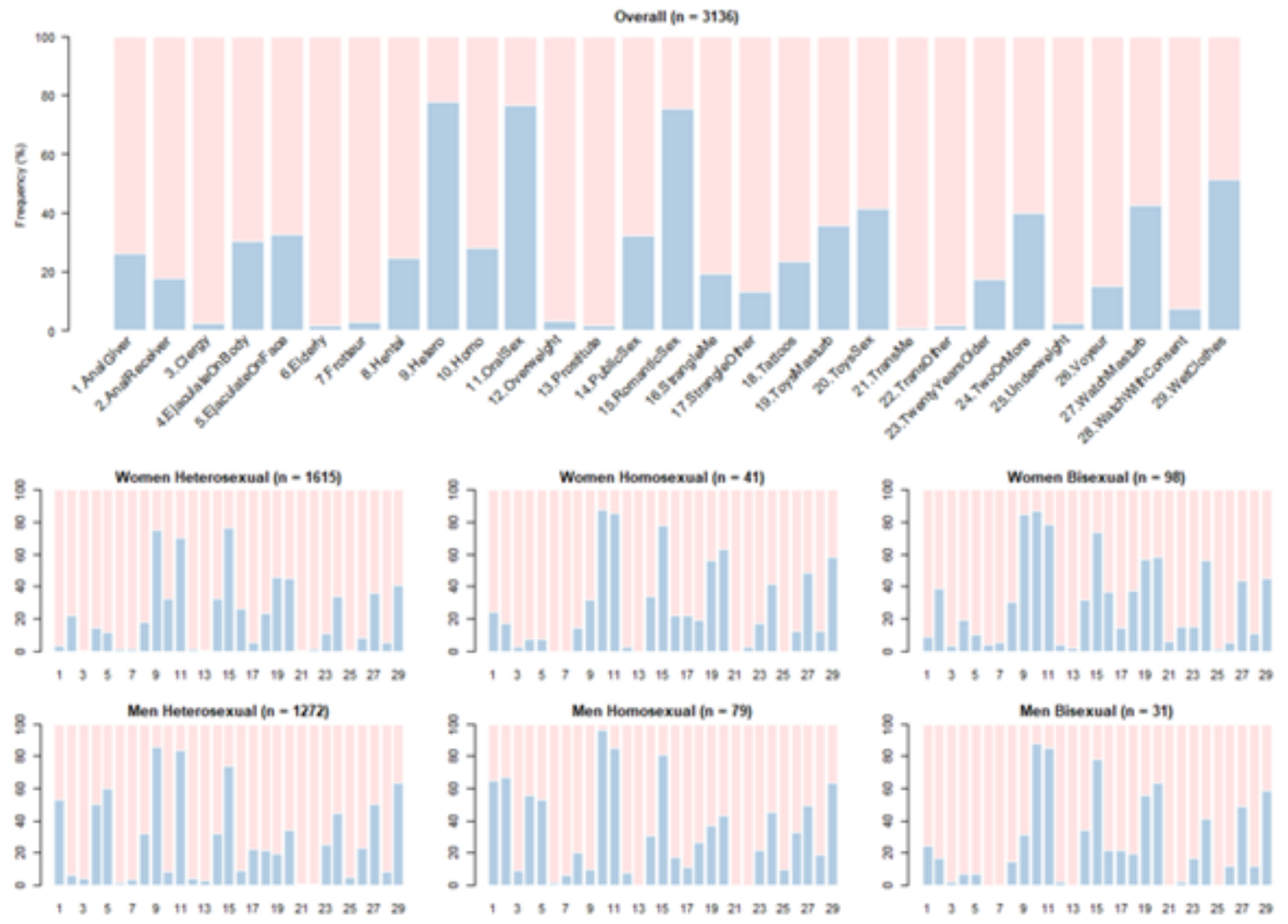

\section{Figure 1}

Prevalence of Arousing Sexual Fantasies in the Overall Sample and Subgroups Note. Blue bars correspond to the percentage of positive answers, while pink bars correspond to the percentage of negative answers. 


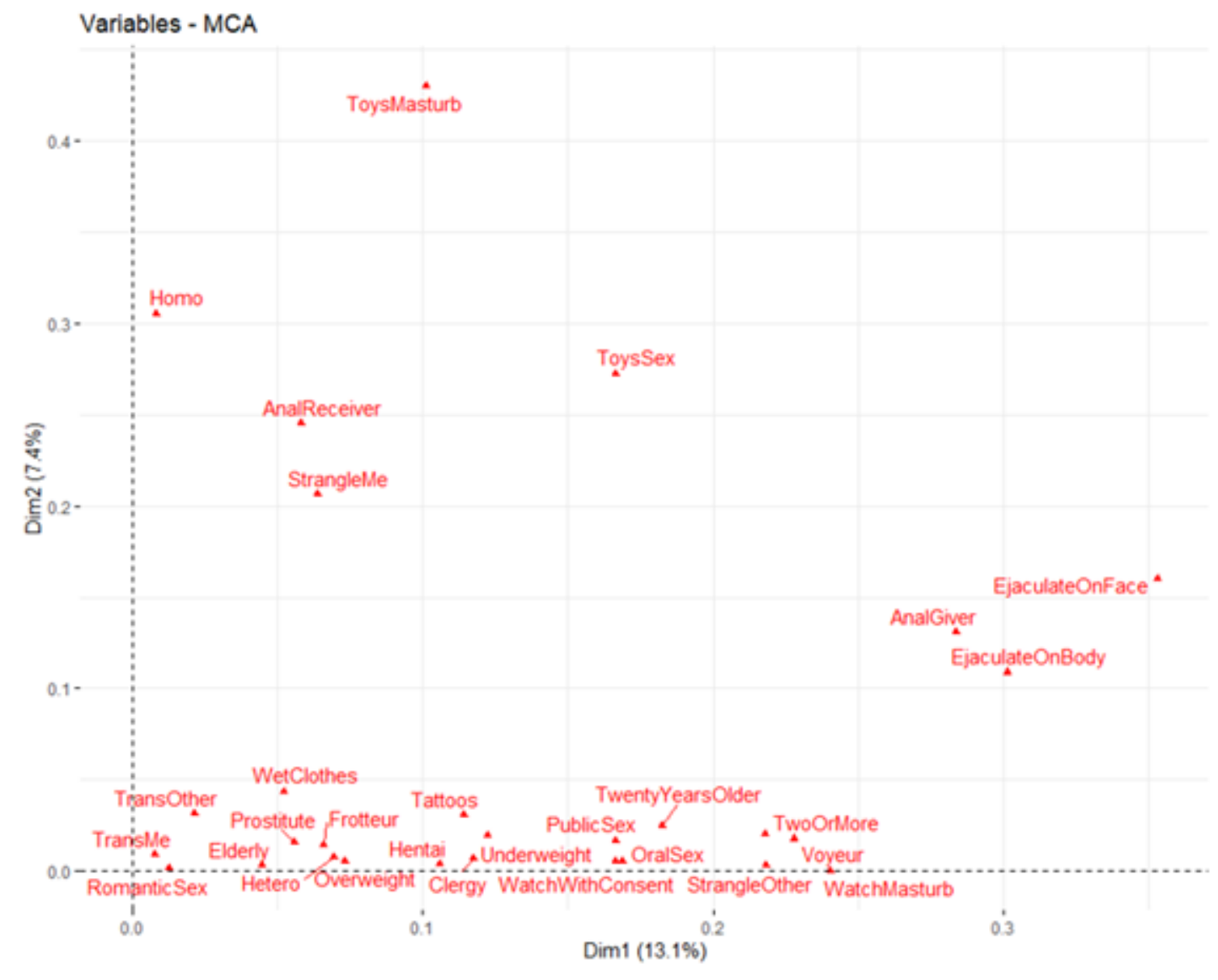

Figure 2

Correlation Between Fantasies and MCA Principal Dimensions 


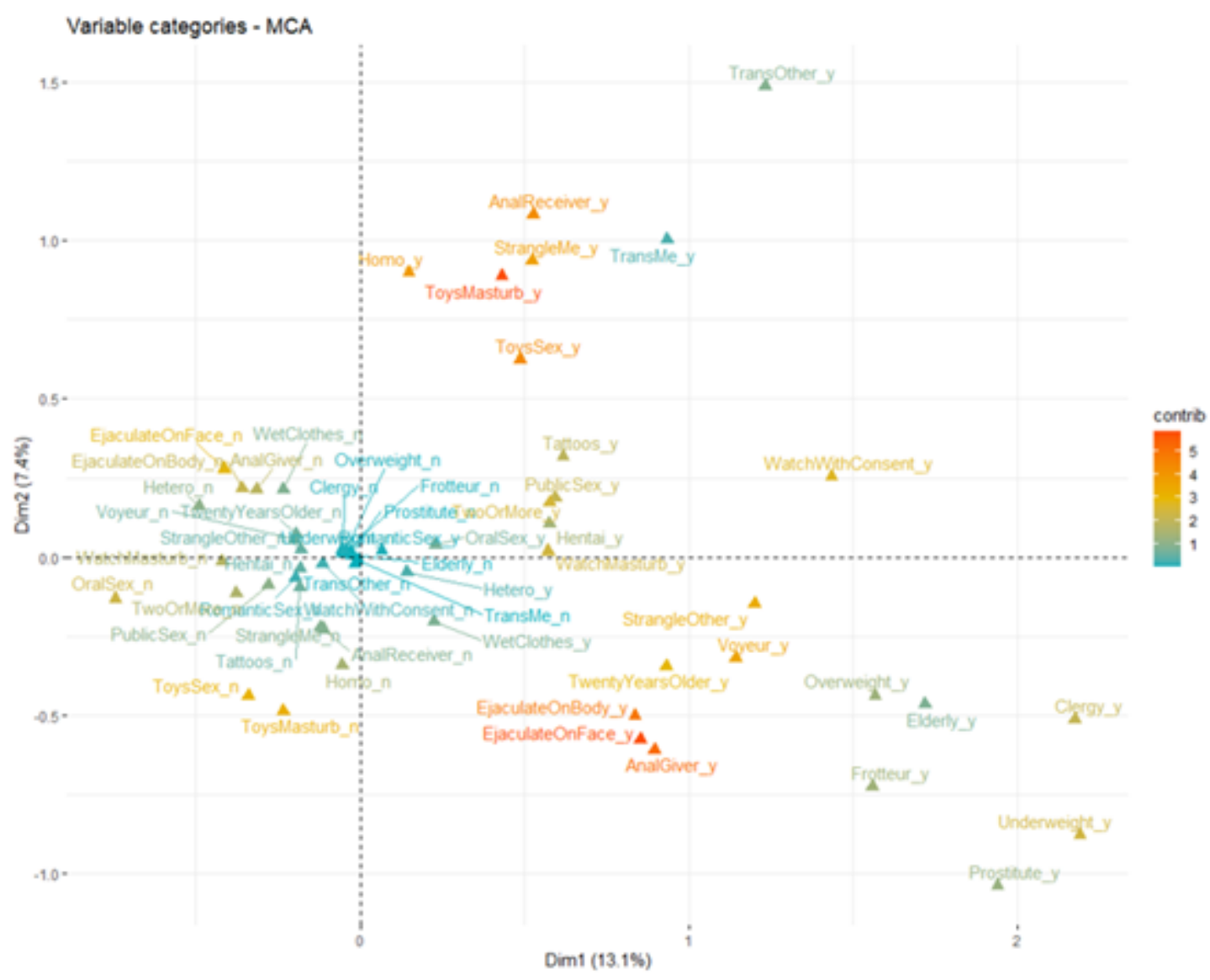

Figure 3

Contribution of Positive and Negative Responses to the MCA Principal Dimensions 


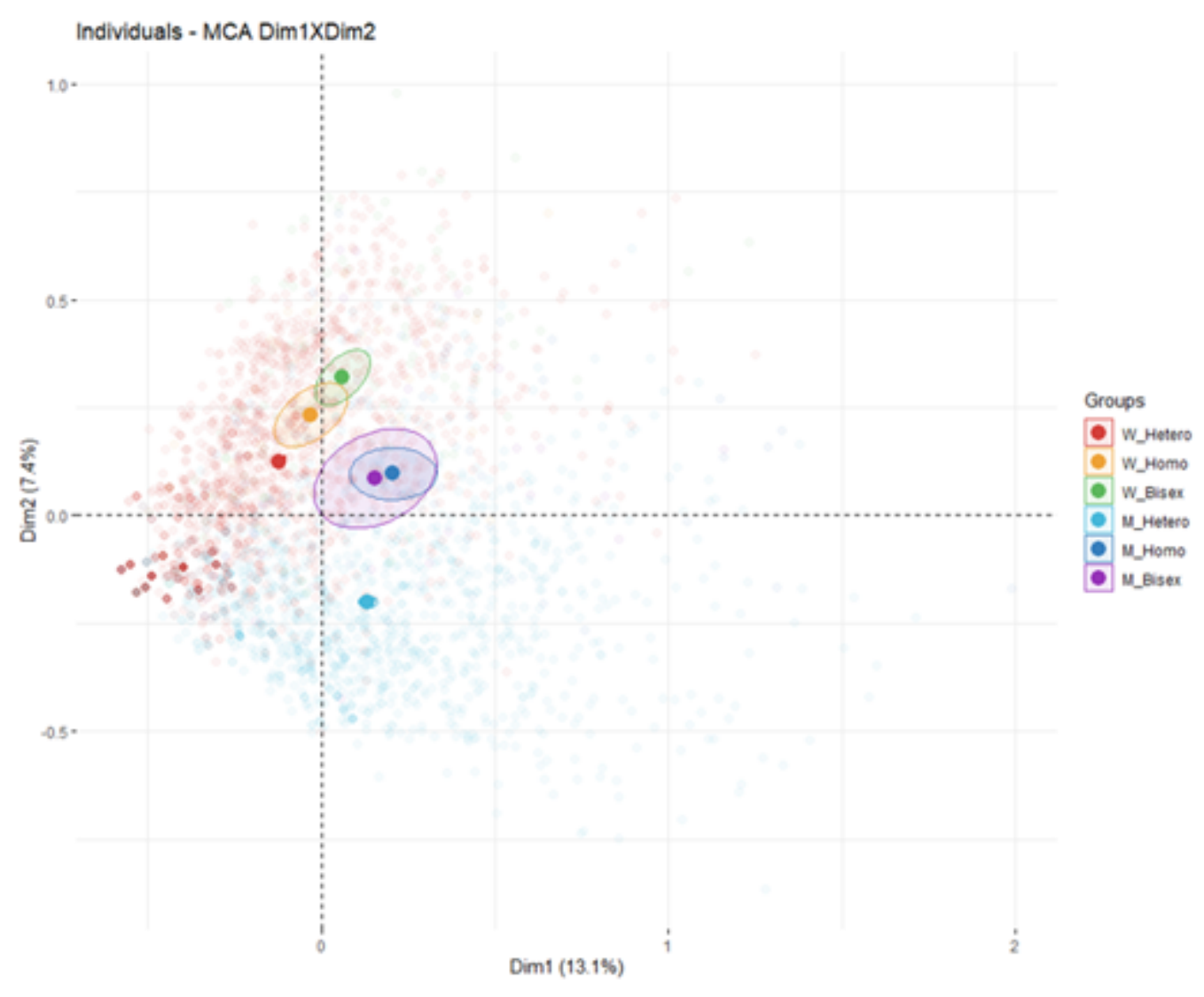

\section{Figure 4}

Individuals and Groups Along the MCA Principal Dimensions. Note. Geometrical representation of individuals and groups along principal MCA dimensions. Ellipses represent the $95 \%$ confidence interval. W_Hetero = heterosexual women; W_Homo = homosexual women/lesbians; W_Bisex = bisexual women; M_Hetero = heterosexual men; M_Homo = homosexual men; M_Bisex = bisexual men . 